\title{
Very strong low temperature bainite
}

\author{
F. G. Caballero, H. K. D. H. Bhadeshia, K. J. A. Mawella, and D. G. Jones, \\ and P. Brown
}

\begin{abstract}
Bainite has been obtained by heat treatment at temperatures as low as $125^{\circ} \mathrm{C}$ in a high carbon, high silicon steel. This has had the effect of greatly refining the microstructure, which is found to have a strength in excess of $2.5 \mathrm{GPa}$ together with an ability to flow plastically before fracture. Such properties have never before been achieved with bainite. In this paper metallographic details are reported of the very fine bainitic microstructure associated with the incredibly low transformation temperature, where during the time scale of the experiments, an iron atom cannot diffuse over a distance greater than $\sim 10^{-17} \mathrm{~m}$. Yet, the microstructure has a scale in the micrometre range, consistent only with a displacive mechanism of transformation.

MST/5034

Dr Caballero (fgc@cenim.csic.es) is in the Department of Physical Metallurgy, Centro Nacional de Investigaciones Metalúrgicas, CSIC, Avda. Gregorio del Amo 8, 28040 Madrid, Spain, Professor Bhadeshia is in the Department of Materials Science and Metallurgy, University of Cambridge, Pembroke Street, Cambridge CB2 3QZ, UK, and Dr Mawella, Mr Jones, and Dr Brown are in the Structural Materials Centre, Defence Evaluation Research Agency, R1079, Building A7, Farnborough GU14 OLX, UK. Manuscript received 20 March 2001; accepted 22 May 2001.
\end{abstract}

(C) 2002 IoM Communications Ltd.

\section{Introduction}

The addition of $\sim 2 \mathrm{wt}-\%$ of silicon to steel enables the production of a distinctive microstructure consisting of a mixture of bainitic ferrite, carbon enriched retained austenite, and some martensite. ${ }^{1-5}$ The silicon suppresses the precipitation of brittle cementite, and hence should lead to an improvement in toughness. However, the full benefit of this carbide free bainitic microstructure has frequently not been realised. This is because the bainite reaction stops well before equilibrium is reached, i.e. when the carbon concentration of the residual austenite reaches a point given by the $T_{\mathrm{o}}$ curve, beyond which diffusionless growth is prevented. This leaves large regions of untransformed austenite that under stress decompose to hard, brittle martensite. $^{6}$

There is, however, a design procedure $e^{6,7}$ that avoids this difficulty in three ways: by adjusting the $T_{\mathrm{o}}$ curve to greater carbon concentrations using substitutional solutes, by controlling the mean carbon concentration, and by minimising the transformation temperature. Steels were designed on this basis and when tested, revealed a reduction in the impact transition temperature of more than $100 \mathrm{~K}{ }^{6,7}$ Fracture toughness measurements confirmed the remarkable levels of toughness that could be achieved, in some cases matching the much more expensive maraging steels. ${ }^{8-10}$ Other aspects of the theory have been verified using a variety of advanced research techniques. ${ }^{11}$

The first major commercial exploitation came with the development of a kinetic theory ${ }^{12}$ to complement the three thermodynamic criteria, so that continuous cooling transformation, which is typical in industry, could be dealt with. More recently, it has been demonstrated experimentally that models based on phase transformation theory can be applied successfully to the design of novel, strong, tough steels. ${ }^{13,14}$ These alloys were designed to ensure that the hardenability is consistent with specific industrial specifications and have achieved the highest ever combinations of strength and toughness for bainitic steels. Toughness values of nearly $130 \mathrm{MPa} \mathrm{m}^{1 / 2}$ have been obtained for strength in the range of $1600-1700 \mathrm{MPa}$. This compares well with maraging steels, which are at least ninety times more expensive.

During the course of this research on the design of bainitic steels, ${ }^{13,14}$ a discovery was made, that very fine bainite can be obtained by transformation at temperatures, as low as $125^{\circ} \mathrm{C}$ during heat treatment for many days. To put this into context, an iron atom diffuses a distance of just $10^{-17} \mathrm{~m}$ during the course of the transformation, even though the resulting bainite has a scale of many micrometres. The aim of this work presented here was to characterise and understand this fine bainitic microstructure in the context of the mechanism of transformation.

\section{Experimental procedures}

The chemical composition of the steel studied was $\mathrm{Fe}-$ $1 \cdot 59 \mathrm{Si}-1.94 \mathrm{Mn}-1 \cdot 33 \mathrm{Cr}-0 \cdot 30 \mathrm{Mo}-0.02 \mathrm{Ni}-0.11 \mathrm{~V}$ (wt- $\%$ ). The alloy was supplied as a cast ingot, specimens of which were then homogenised at $1200^{\circ} \mathrm{C}$ for 2 days while sealed in partially evacuated quartz capsules flushed with argon. The sealed specimens were cooled in air following the homogenisation heat treatment.

The homogenised specimens were austenitised for $15 \mathrm{~min}$ at $1000^{\circ} \mathrm{C}$, and then isothermally transformed at temperatures ranging from 125 to $500^{\circ} \mathrm{C}$ for different times before quenching into water.

Optical microscopy and SEM were used to examine the etched microstructures. Specimens were ground and polished using standard techniques and etched in 2 vol.- $\%$ nital solution and examined using a Jeol JXA 820 SEM operated at $10-15 \mathrm{kV}$. The volume fraction of bainite $V_{\mathrm{b}}$ was estimated by a systematic manual point counting procedure on SEMs. ${ }^{15}$ A grid superimposed on the microstructure provides, after a suitable number of placements, an unbiased statistical estimate of $V_{\mathrm{b}}$. Stereological errors for $V_{\mathrm{b}}$ values correspond to the standard deviation of the measurement.

Quantitative X-ray analysis was used to determine the volume fraction of retained austenite. After grinding and final polishing using $0.25 \mu \mathrm{m}$ diamond paste, the specimens were etched to obtain an undeformed surface. They were then step scanned in a Philips PW 1730 X-ray diffractometer using unfiltered $\mathrm{Cu} K_{\alpha}$ radiation The $2 \theta$ scan rate was $1^{\circ} \mathrm{min}^{-1}$. The machine was operated at $40 \mathrm{kV}$ and $40 \mathrm{~mA}$.

The retained austenite content was calculated from the integrated intensities of (200), (220), and (311) austenite peaks, and those of (002), (112), and (022) planes of ferrite. ${ }^{16}$ Using three peaks from each phase avoids biasing 


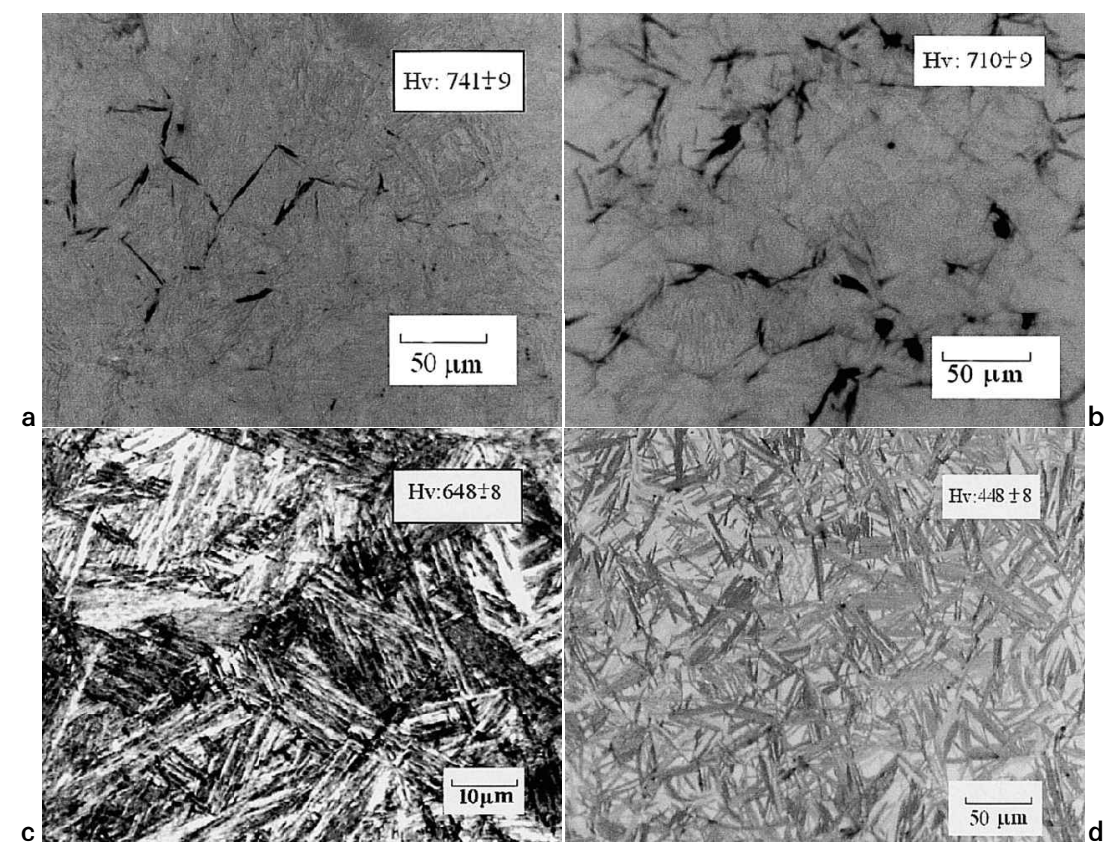

a $125^{\circ} \mathrm{C}$ for 29 days; b $150^{\circ} \mathrm{C}$ for 29 days; c $190^{\circ} \mathrm{C}$ for 2 weeks; $\mathrm{d} 300^{\circ} \mathrm{C}$ for 2 weeks

1 Optical micrographs of isothermal decomposition of austenite: Hv Vickers hardness (30 kg load)

the results owing to any crystallographic texture in the specimens. ${ }^{17}$ The carbon concentration in the austenite and ferrite was estimated using the measured lattice parameters. ${ }^{18}$

Specimens for TEM were machined down to $3 \mathrm{~mm}$ diameter rods. The rods were sliced in to $100 \mu \mathrm{m}$ thick discs and subsequently ground down to foils of $50 \mu \mathrm{m}$ thickness on wet 800 grit silicon carbide paper. These foils were finally electropolished at room temperature until perforation occurred, using a twinjet electropolisher set at a voltage of $40 \mathrm{~V}$. The electrolyte consisted of $5 \%$ perchloric acid, $15 \%$ glycerol, and $80 \%$ methanol (vol.- $\%$ ). Carbon replicas were extracted in 5 vol.- $\%$ hydrochloric acid and 95 vol.- $\%$ methanol. Foils and replicas were examined in a Jeol JEM $200 \mathrm{CX}$ TEM at an operating voltage of $200 \mathrm{kV}$.

The martensite start temperature of the steel was measured using a Thermecmaster $\mathrm{Z}$ thermomechanical simulator. Cylindrical specimens $12 \mathrm{~mm}$ in height and $8 \mathrm{~mm}$ in diameter were heated at a rate of $5 \mathrm{~K} \mathrm{~s}^{-1}$ to $1000^{\circ} \mathrm{C}$ and then cooled at two different rates $\left(40\right.$ and $\left.100 \mathrm{~K} \mathrm{~s}^{-1}\right)$. The formation of martensite during cooling was detected by monitoring the fractional change in dilatation with temperature.

Austenite formation begins during heating at the $A c_{1}$ temperature and is completed when the $A c_{3}$ temperature is reached. Tempering must be carried out below the $A c_{1}$ temperature to avoid the accidental formation of austenite. The austenite formation temperatures were determined using a Thermecmastor $\mathrm{Z}$ simulator. Dilatometric specimens were heated at a rate of $5 \mathrm{~K} \mathrm{~s}^{-1}$ to $1000^{\circ} \mathrm{C}$ and then cooled at $40 \mathrm{~K} \mathrm{~s}^{-1}$. The formation of austenite during heating was detected by monitoring the fractional change in dilatation with temperature. An $A c_{1}$ temperature of $805^{\circ} \mathrm{C}$ and an $A c_{3}$ temperature of $840^{\circ} \mathrm{C}$ were determined from the heating experiment. Specimens were tempered at temperatures ranging from 400 to $700^{\circ} \mathrm{C}$ for $30 \mathrm{~min}$ and $1 \mathrm{~h}$.

Compression tests were carried out at room temperature on specimens transformed isothermally at $190^{\circ} \mathrm{C}$ for 2 weeks. The compression specimens of $5 \mathrm{~mm}$ in diameter and $15 \mathrm{~mm}$ in length were tested in accordance with ASTM E9-89a (Ref. 19) on a $100 \mathrm{kN}$ Mayes servohydraulic machine at a crosshead speed of $1 \mathrm{~mm} \mathrm{~min}^{-1}$. Two specimens were tested in compression. Reliable tensile tests could not be conducted because of extensive casting defects in the form of porosity.

\section{Results and discussion}

\section{MICROSTRUCTURE OF ISOTHERMALLY TRANSFORMED SPECIMENS}

Isothermal transformation in the temperature range $125-300^{\circ} \mathrm{C}$ led to the formation of bainite, as illustrated in the optical micrographs presented in Fig. $1 a-d$. The early stages of transformation are shown in Fig. $1 a$ and $b$ for specimens isothermally heat treated for 29 days at 125 and $150^{\circ} \mathrm{C}$ respectively. Transformation remains incomplete even after 60 days of holding time at $125^{\circ} \mathrm{C}$. Transformation at temperatures much in excess of $300^{\circ} \mathrm{C}$ did not lead to the formation of bainite, suggesting that the bainite start temperature is between $300-350^{\circ} \mathrm{C}$; experiments were conducted up to $500^{\circ} \mathrm{C}$, which revealed only eutectoid decomposition.

Figure 2 shows the evolution of hardness and the fraction of bainite as a function of the isothermal transformation temperature and time. The rate of transformation is fastest when the temperature exceeds $150^{\circ} \mathrm{C}$. For example, it is estimated that the fraction of bainite is 0.8 for transformation at 190 and $250^{\circ} \mathrm{C}$ for 9 and 2 days, respectively. However, a very long heat treatment is required (more than 2 months) to obtain substantial transformation when the temperature is as low as $125^{\circ} \mathrm{C}$. At $300^{\circ} \mathrm{C}$, the maximum volume fraction of bainite formed was 0.6 and 4 days are needed to complete the transformation.

$\mathrm{X}$-ray analysis was used to estimate the quantities of retained austenite present in the microstructure, and its carbon concentration, following two weeks at different temperatures. The experimental results are presented in Table 1 and Figs. 3 and 4. The retained austenite fraction is expected to increase for the higher transformation temperature. This is because less bainite forms at $300^{\circ} \mathrm{C}$, and in contrast to low carbon bainitic steels, the residual austenite is stable to martensitic transformation on cooling to ambient temperature even at the higher bainite transformation temperatures. 

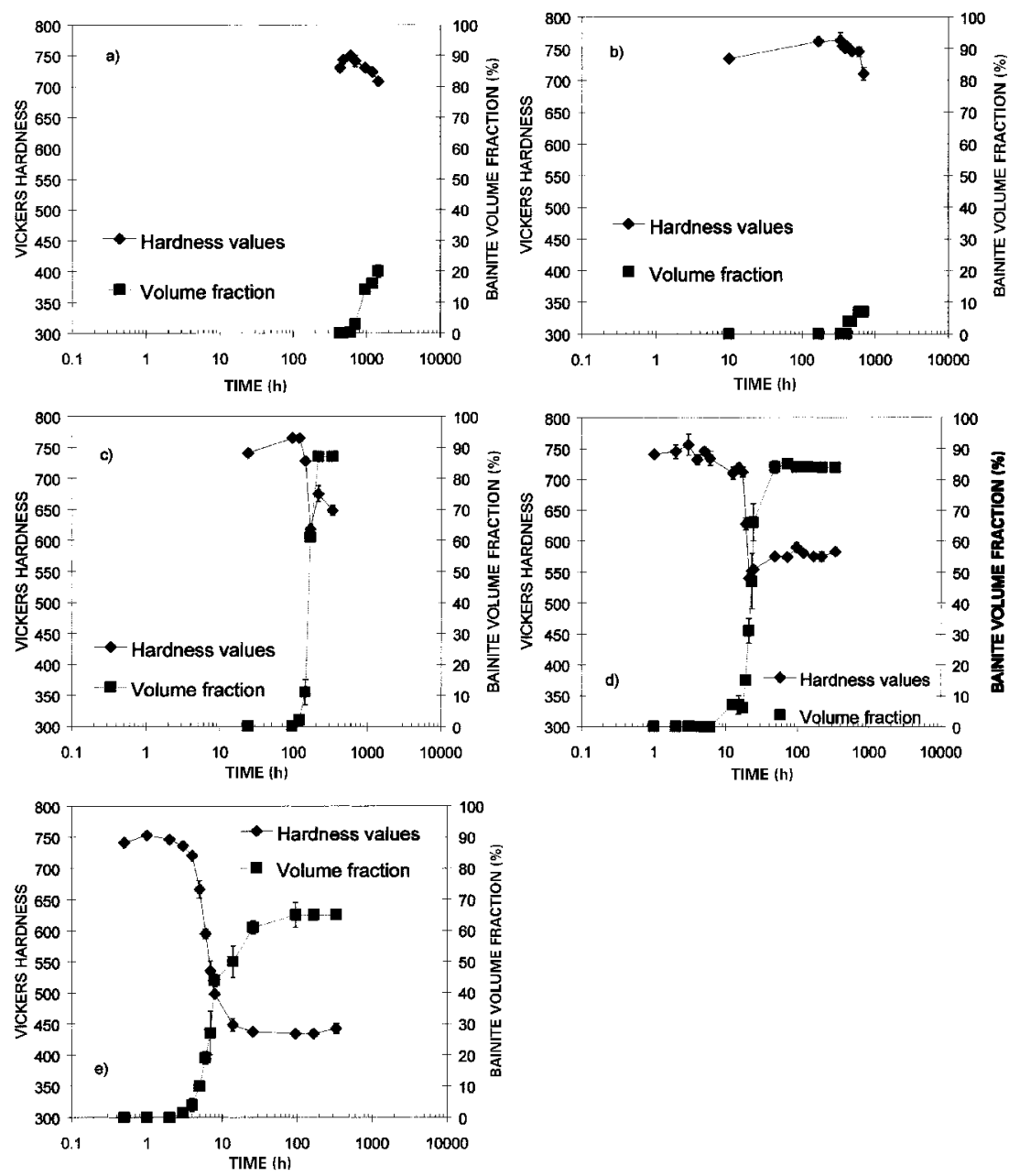

a $125^{\circ} \mathrm{C}$; b $150^{\circ} \mathrm{C}$; c $190^{\circ} \mathrm{C}$; d $250^{\circ} \mathrm{C}$; e $300^{\circ} \mathrm{C}$

2 Plot of hardness ( $30 \mathrm{~kg}$ load) values and bainite volume fraction as function of time at different transformation temperatures

The bainite transformation progresses by the diffusionless growth of tiny platelets known as 'subunits'. The excess carbon in these platelets partitions into the residual austenite soon after the growth event. Diffusionless growth of this kind can only occur if the carbon concentration of the residual austenite is below that given by the $T_{\mathrm{o}}^{\prime}$ curve. The $T_{\mathrm{o}}$ curve is the locus of all points, on a temperature versus carbon concentration plot, where austenite and ferrite of the same chemical composition have the same free energy. The $T_{\mathrm{o}}^{\prime}$ curve is defined similarly but taking into account the stored energy of the ferrite owing to the displacive mechanism of transformation. It follows that the maximum amount of bainite that can be obtained at any temperature is limited by the fact that the carbon content of the residual austenite must not exceed the $T_{\mathrm{o}}^{\prime}$ curve on the phase diagram..$^{20-23}$

The variation of the carbon content of austenite $x_{\gamma}$ as a function of the average carbon content of the alloy $x_{\mathrm{o}}$ and the volume fraction of bainitic ferrite $V_{\mathrm{b}}$ is given by ${ }^{24}$

$$
x_{\gamma}=\bar{x}+V_{\mathrm{b}} \frac{\left(x_{\mathrm{o}}-x_{\alpha}\right)}{\left(1-V_{\mathrm{b}}\right)} \text {. }
$$

Table 1 Experimental quantitative data on microstructure*

\begin{tabular}{lllll}
\hline $\begin{array}{l}\text { Bainite formation } \\
\text { temperature, }{ }^{\circ} \mathrm{C}\end{array}$ & $\mathrm{V}_{\gamma}$ & $\mathrm{V}_{\mathrm{b}}$ & $\mathrm{x}_{\gamma^{\prime}}$ wt-\% & $\mathrm{x}_{\alpha^{\prime}}$ wt-\% \\
\hline 300 & $0.35 \pm 0.01$ & $0.65 \pm 0.01$ & $1.69 \pm 0.10$ & $0.20 \pm 0.07$ \\
250 & $0.16 \pm 0.01$ & $0.84 \pm 0.01$ & $1.76 \pm 0.10$ & $0.32 \pm 0.07$ \\
190 & $0.13 \pm 0.01$ & $0.87 \pm 0.01$ & $1 \cdot 72 \pm 0.10$ & $0.32 \pm 0.07$
\end{tabular}

$* \mathrm{~V}_{\gamma}$ volume fraction of austenite. where $x_{\alpha}$ is the amount of carbon trapped in the bainitic ferrite and $\bar{x}$ is the overall amount of carbon in the steel.

The fact that the measured carbon concentrations of the retained austenite in Fig. 4 lie between the $T_{\mathrm{o}}$ and the paraequilibrium $\mathrm{Ae}_{3}$ phase boundaries is consistent with a mechanism in which the bainite grows without any diffusion, but with excess carbon partitioning in to the austenite soon after transformation. It is for this reason that the

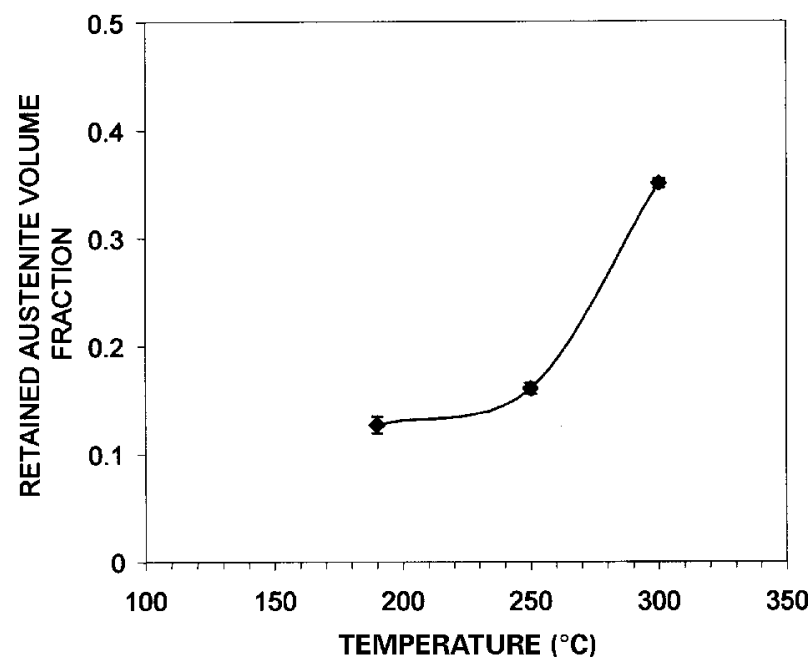

3 Plot of volume fraction of retained austenite as function of isothermal transformation temperature 


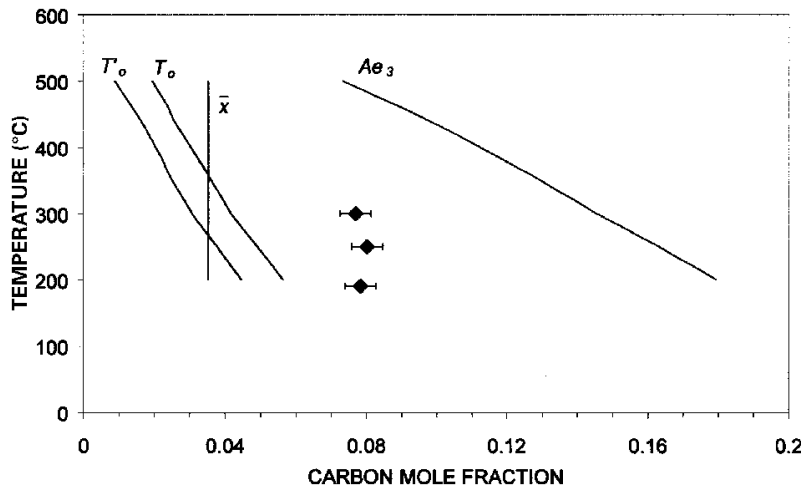

4 Calculated $\mathrm{T}_{0}^{\prime}, \mathrm{T}_{\mathrm{o}}$, and paraequilibrium $\mathrm{Ae}_{3}$ curves for studied steel and experimental data for carbon composition of retained austenite in specimens heat treated for 2 weeks at different temperatures: $\bar{x}$ represents overall carbon content of steel; phase boundaries were calculated as in Ref. 25

bainite reaction remains incomplete, with the maximum fraction limited by a boundary well below the paraequilibrium $\mathrm{Ae}_{3}$ phase boundary. ${ }^{25}$ The fact that the measured carbon concentrations of the austenite exceed the $T_{\mathrm{o}}$ concentration is a consequence of the fact that the isolated films of austenite between the bainite plates can accumulate carbon, beyond $T_{\mathrm{o}}$ (Ref. 26). They cannot, of course, transform to bainite once the $T_{\mathrm{o}}$ curve is exceeded.

According to the experimental data in Table 1, despite the quite large fraction of bainite, austenite is not greatly enriched in carbon. This can only be possible if a substantial quantity of carbon is trapped in the bainitic ferrite. Experimental results in Table 1 reveal this carbon in solid solution in the ferrite and Fig. 5 confirms the presence of some cementite in the bainitic ferrite, in the specimen isothermally transformed at $190^{\circ} \mathrm{C}$ for 2 weeks. The carbides are extremely fine, approximately $20 \mathrm{~nm}$ wide and $175 \mathrm{~nm}$ long. These observations explain the small extent of carbon enrichment detected in the residual austenite.

Using all these experimental data, the time - temperaturetransformation (TTT) diagram of the steel was calculated ${ }^{25}$ and compared against the experimental data (Fig. 6). The curves represent the initiation of transformation whereas the points all represent a finite amount of bainite (a volume fraction of $\sim 0.05$ ); in the circumstances, the agreement between the measured data and the calculated TTT curve is considered reasonable.

\section{MECHANICAL PROPERTIES}

As mentioned above, the bainite that forms has a very fine microstructure because of the low transformation temperatures. This is illustrated in the TEMs shown in Fig. 7. Quite remarkably, the bainite plates formed at $190^{\circ} \mathrm{C}$ have a width that is less than $50 \mathrm{~nm}$, with each plate separated by an even finer film of retained austenite. Not surprisingly, the fine microstructure leads to a very high strength.

Figure 8 shows the compression curve of the microstructure formed by transformation at $190^{\circ} \mathrm{C}$ for 2 weeks; a view of the specimen after testing is shown in Fig. 9. The specimen clearly has considerable plasticity for deformation at room temperature even though the yield strength in compression is $\sim 2000 \mathrm{MPa}$.

\section{TEMPERING EXPERIMENTS}

Experiments were carried out to study the stability of the microstructure to tempering heat treatments. Figure 10 shows the hardness as a function of the tempering temperature. The experiments were conducted on the bainitic

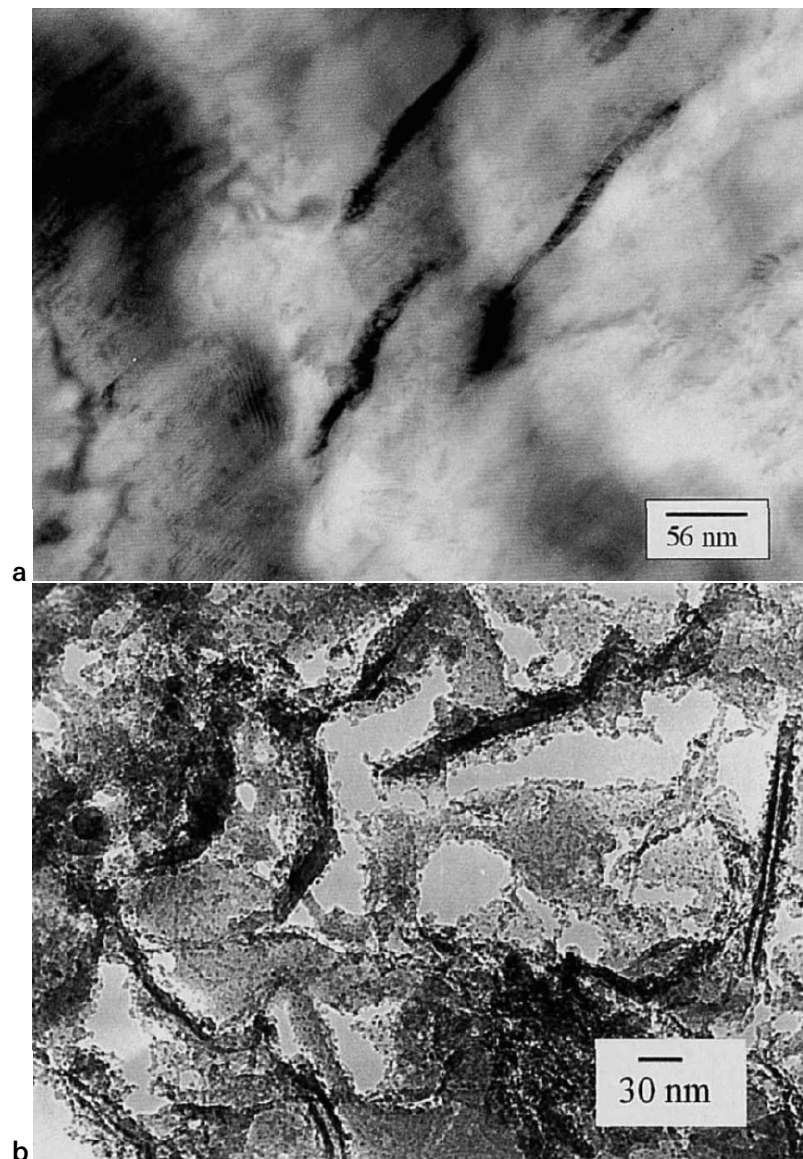

a thin foil; b carbon extraction replica

5 Micrographs of some carbides precipitated in bainitic ferrite in microstructure formed at $190^{\circ} \mathrm{C}$ for 2 weeks (TEM)

microstructure formed at $190^{\circ} \mathrm{C}$ for 2 weeks. Tempering that microstructure at temperatures lower than $500^{\circ} \mathrm{C}$ for $30 \mathrm{~min}$ did not result in any significant loss of hardness.

\section{Conclusions}

Bainite has been obtained by transformation at temperatures as low as $125^{\circ} \mathrm{C}$ in a high carbon, high silicon steel.

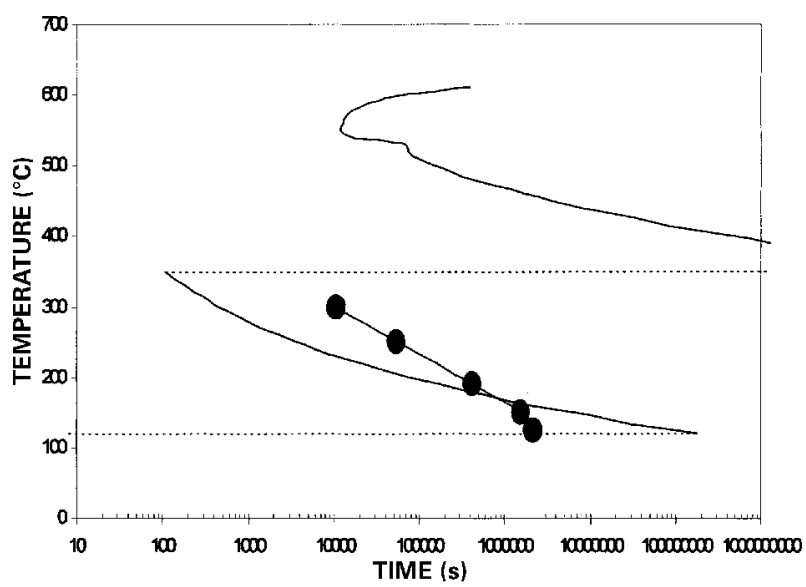

6 Calculated time-temperature-transformation diagram of steel: points in graphs represent start and finish time for bainite transformation 


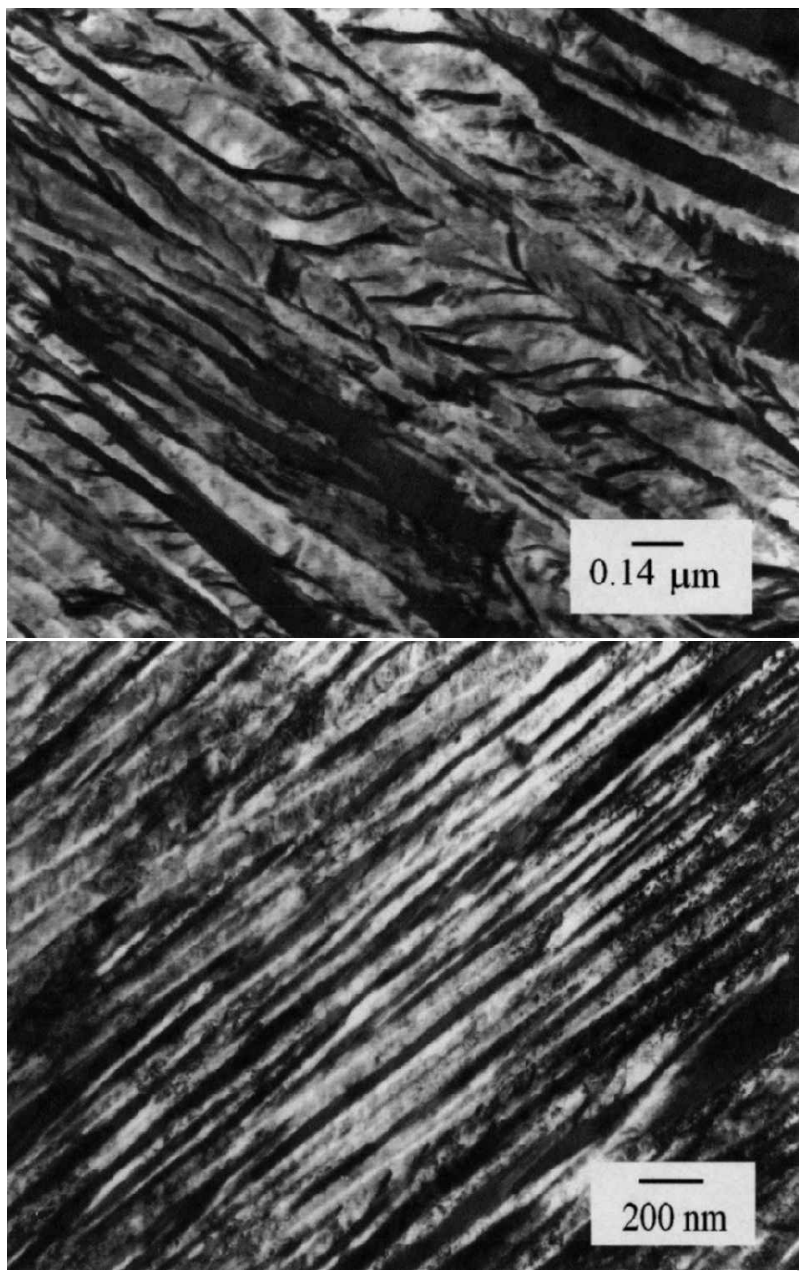

7 Thin foil TEMs of microstructure obtained at $190^{\circ} \mathrm{C}$ for 2 weeks

The bainite plates thus obtained are incredibly fine, with a width of some $50 \mathrm{~nm}$, giving a very high strength in excess of $2.5 \mathrm{GPa}$ and perceptible ductility. Such properties have never been achieved with bainite. It is the intention now to design new alloys using the theory of the bainite reaction, for creating a new class of ultrahigh strength steels and then to conduct comprehensive mechanical and microstructural tests.

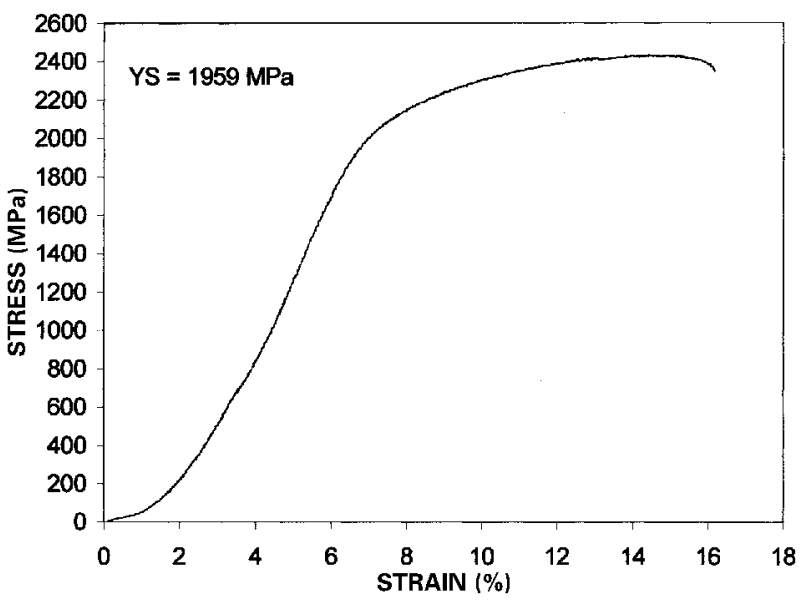

8 Compression curve for microstructure formed at $190^{\circ} \mathrm{C}$ for 2 weeks: YS yield stress

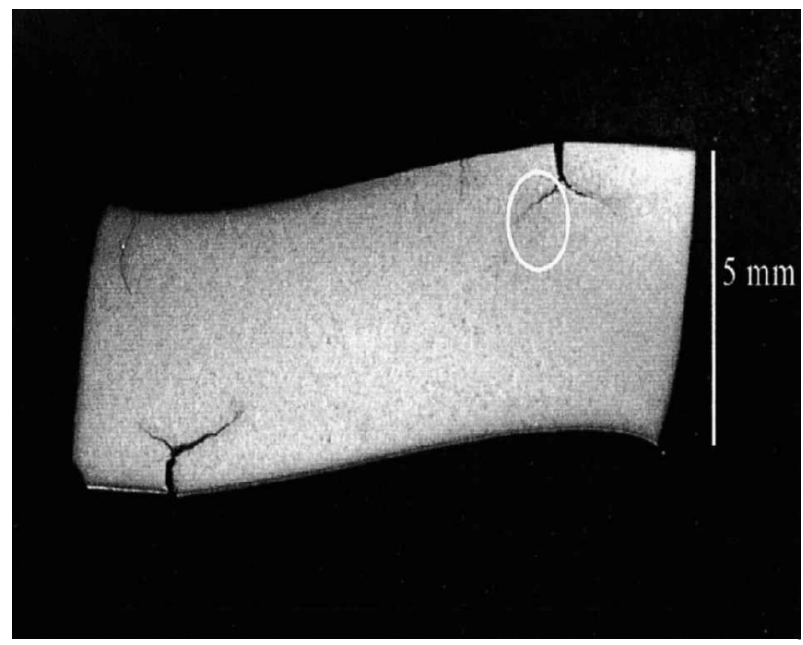

9 Compression specimen after testing

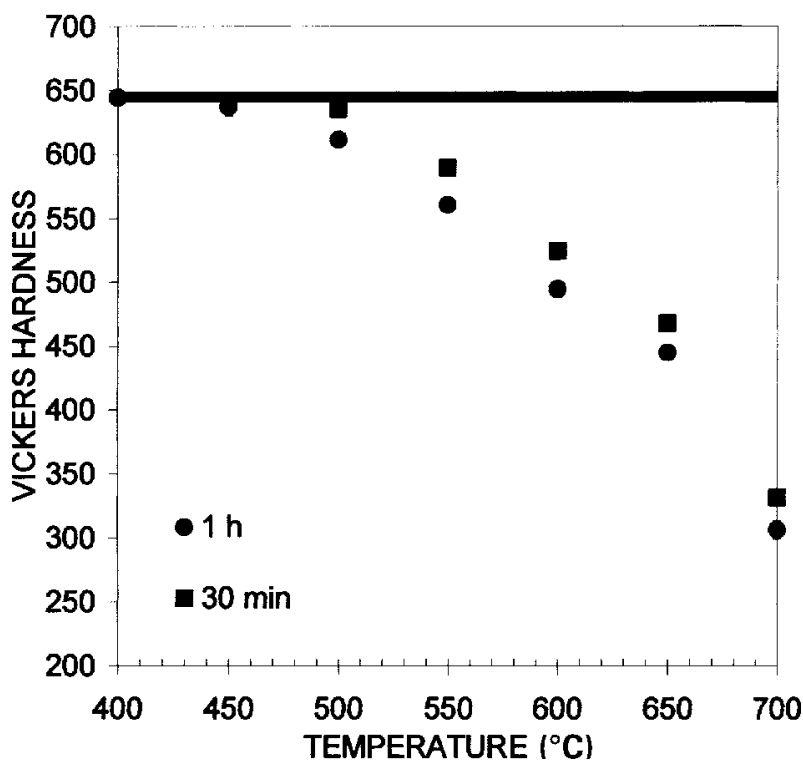

10 Plot of hardness values (30 kg load) as function of tempering: horizontal line represents hardness of microstructure formed at $190^{\circ} \mathrm{C}$ for 2 weeks

\section{Acknowledgements}

This work was carried out as part of Technology Group 4 (Materials and Structures) of the MoD Corporate Research Programme. The authors would like to thank Professor Alan Windle for the provision of laboratory facilities at the University of Cambridge.

\section{References}

1. S. J. MATAS and R. F. HEHEMANN: Trans. AIME, 1961, 221, $179-$ 185.

2. R. ENTIN: in 'Decomposition of austenite by diffusional processes', (ed. V. F. Zackay and H. I. Aaronson), 295-311; 1962, New York, NY, Interscience.

3. R. F. HEHEMANN: in 'Phase transformations', 397-432; 1970, Metals Park, $\mathrm{OH}$, American Society for Metals.

4. T. LYMAN and A. R. TROIANO: Trans. AIME, 1945, 162, 196.

5. R. Lehouillier, G. BeGiN, and A. Dube: Metall. Trans. A, 1971, 2A, 2645. 
6. H. K. D. H. BHADESHIA and D. v. EDMONDS: Met. Sci., 1983, 17, $411-419$.

7. H. K. D. H. BHADESHIA and D. V. EDMONDS: Met. Sci., 1983, 17, $420-425$.

8. V. T. T. MIIHKINEN and D. V. EDMONDS: Mater. Sci. Technol., $1987,3,422-431$

9. V. T. T. MIIHKINEN and D. V. EDMONDS: Mater. Sci. Technol., $1987,3,432-440$

10. V. T. T. MIIHKINEN and D. V. EDMONDS: Mater. Sci. Technol., $1987,3,441-449$.

11. H. K. D. H. BHADESHIA: 'Bainite in steels: transformations, microstructure, and properties', 2nd edn; 2001, London, The Institute of Materials.

12. H. K. D. H. BHADESHIA: in 'Modelling and simulation for materials design', (ed. S. Nishijima and H. Onodera), 227 -232; 1996, Japan, National Research Institute for Metals.

13. F. G. CABAllero, H. K. D. H. BHADESHia, K. J. A. MAWELla, D. G. JONES, and P. BROWN: Mater. Sci. Technol., 2001, 17, 512-516.

14. F. G. CABAllero, H. K. D. H. BHADESHia, K. J. A. MAWELla, D. G. JONES, and P. BROWN: Mater. Sci. Technol., 2001, 17, $517-522$.
15. G. F. VANDER VOORT: 'Metallography: principles and practice', 427; 1984, New York, NY, McGraw-Hill.

16. J. DURNIN and K. A. RIDAL: J. Iron Steel Inst., 1968, 206, 60

17. M. J. DICKSON: J. Appl. Cryst., 1969, 2, $176-180$.

18. D. J. DYSON and B. HOLMES: J. Iron Steel Inst., 1970, 208, 469.

19. Standard E9-89a, ASTM, Philadelphia, PA, 1995.

20. H. K. D. H. BHADESHIA: Acta Metall., 1981, 29, $1117-1130$.

21. H. K. D. H. BHADESHIA and A. R. WAUGH: Acta Metall., 1982, 30, $775-784$.

22. L. C. Chang and H. K. D. H. Bhadeshia: Mater. Sci. Eng. A, 1994, A184, L17 - 20.

23. I. STARK, G. D. W. SMITH, and H. K. D. H. BHADESHIA: in 'Solid $\rightarrow$ solid phase transformations', (ed. G. W. Lorimer), $211-215 ; 1988$, London, The Institute of Metals.

24. H. K. D. H. BHADESHIA and D. V. EDMONDS: Acta Metall., 1980, 28, $1265-1273$.

25. H. K. D. H. BHADESHIA: in 'Materials algorithms project', www.msm.cam.ac.uk/map/steel/programs/mucg46-b.html

26. H. K. D. H. BHADESHIA and A. R. WAUGH: Acta Metall., 1982, 30, $775-784$. 